\title{
Juventude brasileira e o trabalho no tráfico de drogas: pauperização, precarização e superexploração
}

\section{Brazilian Youth and the Work in Drug Trafficking: Pauperization, Precarisation and Super-Exploitation}

\author{
Pedro Henrique Antunes da Costa (orcid.org/0000-0003-2404-8888) ${ }^{1}$ \\ Kíssila Teixeira Mendes (orcid.org/0000-0002-7817-599X)² \\ Ítalo de Oliveira Guedes (orcid.org/0000-0001-7491-7266)33
}

\begin{abstract}
Resumo
O presente trabalho visa apresentar elementos para a compreensão da dinâmica de trabalho no tráfico da juventude brasileira em condições pauperizadas. É um exercício teórico-analítico, baseado em revisão crítica da literatura e a partir de pressupostos, conceitos e categorias da tradição marxista, com destaque para a discussão sobre trabalho e superpopulação relativa, de Marx, e superexploração da força de trabalho, de Marini. As relações e condições de trabalho imperantes no tráfico para parte desses jovens pauperizados, predominantemente negros e periféricos, configuram a intensificação da precariedade e superexploração da força de trabalho, seguindo a própria dinâmica do mundo do trabalho e projeto neoliberal, de acordo com as particularidades da condição de capitalismo dependente do Brasil. Não à toa, o tráfico se abastece, prioritariamente, dessa parcela populacional, apresentando-se como opção viável e possibilidade de "ascensão social", diante das inexistentes, parcas e precarizadas opções do mercado formal e informal de trabalho.
\end{abstract}

Palavras-chave: Tráfico de drogas. Condições de trabalho. Juventude.

\begin{abstract}
This study aims to present elements to understand the work dynamics in drug trafficking by Brazilian youth in poor conditions. This is a theoretical-analytical study, based on a critical review of the literature and on assumptions, concepts and categories of the Marxist tradition, emphasising Marx's discussion about work and relative superpopulation, and the super-exploitation of the labor force, by Marini. The relations and work conditions that prevail on drug trafficking for a lot of this poor youth, predominantly black and peripheral, configurate the
\end{abstract}

\footnotetext{
1 Universidade de Brasília, Distrito Federal, Brasil. E-mail: phantunes.costa@gmail.com.

2 Universidade Federal de Juiz de Fora, Juiz de Fora, Brasil. E-mail: kissilamm@hotmail.com.

${ }^{3}$ Universidade Federal da Paraíba, João Pessoa, Brasil. E-mail: italogueds@gmail.com.
} 
intensification of precariousness and super-exploitation of the work force, following the dynamics of the "work world" and neoliberalism, according to the peculiarities of the dependent capitalism condition of Brazil. Drug trafficking is supplied primarily by this population, appearing as a viable option and a possibility of "social ascension", considering the nonexistent, sparse and precarious options of the formal and informal labor market.

Keywords: Drug traffic. Working conditions. Youth.

O presente trabalho se debruça sobre a relação entre juventude, trabalho e tráfico de drogas ilícitas no Brasil contemporâneo. Objetivamos apresentar algumas pistas para a compreensão da dinâmica de inserção e trabalho dessa juventude no tráfico, em especial a que se encontra em condições pauperizadas. Partimos do pressuposto de que o tráfico se constitui também como uma forma de trabalho, o que torna relevante as seguintes indagações: quem são esses jovens e por que eles? Em que sentido as transformações na esfera produtiva e reprodutiva das últimas décadas, oriundas da crise do capitalismo monopolista dos anos 1970 - e intensificadas recentemente -, refletem na juventude, no tráfico de drogas e se utilizam de ambos? Como tais elementos se atrelam às próprias estruturas antagônicas do Brasil e sua condição dependente?

Trata-se de um exercício teórico analítico, que se valeu de uma revisão narrativa da literatura, sendo coletados e analisados artigos, livros, dissertações, teses e relatórios encontrados por meio de buscas na base de dados SciELO, com complementações no Google Acadêmico e indicações de especialistas. Segundo Rother (2004, p. v), esse tipo de revisão, de caráter não sistemático, é propício para a descrição, análise e discussão crítica de "determinado assunto, sob ponto de vista teórico ou contextual". Para a busca, utilizamos os termos "tráfico de drogas" e "juventude" associados. Incluímos pesquisas empíricas ou revisões da literatura que abordassem a dinâmica de trabalho de jovens no tráfico de drogas na realidade brasileira, sem recorte temporal. Tal processo foi efetuado entre fevereiro e abril de 2019.

Os estudos selecionados (Quadro 1) foram lidos na íntegra, com a análise direcionada para a discussão sobre a dinâmica precária desse trabalho da juventude no tráfico e seu caráter de superexploração da força de trabalho, interligado à ilegalidade. A fundamentação analítica foi de pressupostos, conceitos e categorias da tradição marxiana e marxista, com 
destaque para a discussão sobre o trabalho e a superpopulação relativa, oriundas do próprio Marx, e a superexploração da força de trabalho em nossa condição de capitalismo dependente, trabalhada por Ruy Mauro Marini no âmbito da Teoria Marxista da Dependência (TMD).

Quadro 1. Trabalhos incorporados para análise

\begin{tabular}{|c|c|c|}
\hline Autores & Data & Título \\
\hline Alberto, M. F. P., \& Pessoa, M. C. B. & 2018 & $\begin{array}{l}\text { Trabalho infantil no tráfico de drogas: o } \\
\text { que diz a produção acadêmica? }\end{array}$ \\
\hline Barcinski, M, \& Cúnico, S. D. & 2016 & $\begin{array}{l}\text { Retratos da vitimização e do } \\
\text { protagonismo feminino }\end{array}$ \\
\hline Bortolozzi, R. M. & 2014 & $\begin{array}{l}\text { Sentido do trabalho para jovens } \\
\text { trabalhadores da economia da droga: } \\
\text { exame retrospectivo }\end{array}$ \\
\hline $\begin{array}{l}\text { Brasil. Ministério dos Direitos } \\
\text { Humanos }\end{array}$ & 2018 & Levantamento Anual Sinase 2016 \\
\hline Cortina, M. O. C. & 2015 & $\begin{array}{l}\text { Mulheres e tráfico de drogas: } \\
\text { aprisionamento e criminologia feminista }\end{array}$ \\
\hline $\begin{array}{l}\text { Cruz Neto, O., Moreira, M. R., \& } \\
\text { Sucena, L. F. M. }\end{array}$ & 2001 & $\begin{array}{l}\text { Nem soldados nem inocentes: juventude e } \\
\text { tráfico de drogas no Rio de Janeiro }\end{array}$ \\
\hline Faria, A. A. C., \& Barros, V. A. & 2011 & $\begin{array}{l}\text { Tráfico de drogas: uma opção entre } \\
\text { escolhas escassas }\end{array}$ \\
\hline Feffermann, M. & 2008 & $\begin{array}{l}\text { Cotidiano dos jovens trabalhadores do } \\
\text { tráfico }\end{array}$ \\
\hline Fraga, P. C. P, \& Silva, J. K. N. & 2017 & $\begin{array}{l}\text { A participação feminina em mercados } \\
\text { ilícitos de drogas no Vale do São } \\
\text { Francisco, no Nordeste brasileiro }\end{array}$ \\
\hline Fraga, P. C. P. & 2003 & $\begin{array}{l}\text { Da favela ao sertão: juventude, tráfico e } \\
\text { institucionalidade }\end{array}$ \\
\hline Helpes, S. S. & 2014 & $\begin{array}{l}\text { Vidas em jogo: um estudo sobre mulheres } \\
\text { envolvidas com o tráfico }\end{array}$ \\
\hline Meirelles, Z. V. & 2008 & $\begin{array}{l}\text { Nas viradas da vida: jovens que romperam } \\
\text { com o mercado do tráfico de drogas em } \\
\text { favelas na cidade do Rio de Janeiro }\end{array}$ \\
\hline $\begin{array}{l}\text { Ministério da Justiça e Segurança } \\
\text { Pública }\end{array}$ & 2017 & $\begin{array}{l}\text { Levantamento Nacional de informações } \\
\text { penitenciárias / Infopen }\end{array}$ \\
\hline Rocha, A. P. & 2013 & $\begin{array}{l}\text { Proibicionismo e a criminalização de } \\
\text { adolescentes pobres por tráfico de drogas }\end{array}$ \\
\hline Rocha, A. P. & 2015 & $\begin{array}{l}\text { Relações de trabalho no tráfico: } \\
\text { exploração, riscos e criminalização }\end{array}$ \\
\hline Rodrigues, L. B., \& Fraga, P. C. P. & 2018 & Justiça e variáveis legais: processos contra \\
\hline
\end{tabular}




\begin{tabular}{|l|c|l|}
\hline & & $\begin{array}{l}\text { adolescentes varejistas do tráfico de } \\
\text { drogas }\end{array}$ \\
\hline Souza, K. O. J. & 2009 & $\begin{array}{l}\text { A pouca visibilidade da mulher brasileira } \\
\text { no tráfico de drogas }\end{array}$ \\
\hline Vilela, T., \& Barros, V. A. & 2016 & $\begin{array}{l}\text { O acerto de contas no trabalho do tráfico } \\
\text { de drogas varejista }\end{array}$ \\
\hline $\begin{array}{l}\text { Willadino, R., Nascimento, R. C., \& } \\
\text { Silva, J. S. }\end{array}$ & 2018 & $\begin{array}{l}\text { Novas configurações das redes criminosas } \\
\text { após a implantação das UPPs }\end{array}$ \\
\hline
\end{tabular}

Fonte: Elaborada pelos autores

Circunscrito à totalidade social capitalista em seu atual estágio de desenvolvimento, e a partir das particularidades brasileiras, tomamos o trabalho juvenil no tráfico de drogas como objeto de estudo. Para isso, traçaremos alguns aspectos gerais acerca da categoria trabalho nesse modo de produção e reprodução da vida e a sua relação com o tráfico de drogas ilícitas; depois, adentraremos nos resultados propriamente ditos e sua discussão. Apresentaremos um panorama sobre juventude e tráfico de drogas no país, buscando explicitar o perfil e condições de vida desses sujeitos, assim como discorrer sobre as relações que estabelecem com o fluxo ilegal de substâncias psicoativas, especialmente no comércio varejista, à luz da fundamentação teórica supracitada. Por fim, realizamos uma síntese, com apontamentos para a compreensão e abordagem do tema.

\section{Considerações iniciais sobre trabalho e tráfico de drogas}

Para Marx e a tradição marxista, a categoria trabalho é central na compreensão do ser humano, como condição de realização de si e fonte afirmadora da vida. Nos Manuscritos Econômico-Filosóficos, ele a define como dimensão ontológica fundamental, sendo o que diferencia o homem do animal, pois, a partir da relação de transformação da natureza, o homem se torna um ser universal (e não mais objetivo) e pode dar rumos livres à sua existência e atividade vital consciente (Marx, 1844/2010). Assim, define a importância do trabalho para a existência do homem, fundamentalmente, por mediar sua relação com a natureza. 
Essa definição clássica de trabalho, tida como "positiva", tem um contraponto "negativo", pois, embora o desenvolvimento dos meios de produção reflita a história humana, por outro lado, Marx também define o trabalho na sociabilidade capitalista como mortificação do homem e subordinação ao capital, na medida em que ele se torna alienado, seja do fruto de seu trabalho (as mercadorias que produz), de si mesmo, dos outros e, logo, do próprio gênero humano. As relações de produção, em vez de serem dominadas pelo homem, o dominam, e o trabalhador se torna mais uma mercadoria - mais barata do que as que cria -, o que tem como consequência a supervalorização do mundo das coisas, em detrimento da valorização do ser humano (Marx, 1844/2010). O homem, dessa forma, passa a satisfazer suas funções animais, tornando o trabalho uma atividade de mortificação; a partir desse trabalho alienado, ele perde sua consciência de ser social e parte para uma vida egoísta.

$\mathrm{Na}$ presente conjuntura, pensar o trabalho significa se debruçar em suas formas e modulações históricas e como estas desaguam no atual momento histórico. Considerando nosso objetivo e a impossibilidade de um resgate e tratado histórico, voltamos à para década de 1970, que demarca a crise do capitalismo monopolista e seu rígido modelo fordista, bem como dos regimes de bem-estar social no centro do capitalismo mundial. As quedas nas taxas de lucro e as altas nas de inflação, entre outros elementos, marcam tal panorama e demonstram a incapacidade de sustentar os patamares de acumulação capitalista. Como consequência, temos um processo de reestruturação produtiva, por meio da acumulação flexível nos processos e mercados de trabalho, produtos e padrões de consumo, e a ascensão do neoliberalismo (Harvey, 1998). Com o fim do ciclo de produção fordista e emergência da Revolução Tecnológica, uma nova fase de reestruturação capitalista se deu com o ganho de força das corporações transnacionais e a ultramonopolização privada, atrelando-se ao desmonte dos direitos sociais, o combate ao sindicalismo e recusa às propostas socialistas e a propagação de valores subjetivistas e individualistas (Antunes, 2015).

Nessa conjuntura, marcada pela internacionalização, dá-se um novo desdobramento da questão social, sobretudo do desemprego estrutural, com a intensificação dos sobrantes, não filiados ao mercado de trabalho formal e ligados à informalidade pelos processos de 
flexibilização e precarização. Vale ressaltar que essas mutações ganham força no Brasil nos anos 1990. Antunes (2015) analisa como a reestruturação produtiva no contexto neoliberal produziu mudanças significativas no mundo do trabalho, como o desemprego, a flexibilização e a precarização das relações trabalhistas. A escala e lógica de produção globalizada de mercadorias, a perda de direitos e pioras nas condições de vida têm gerado uma sociedade de precarizados, afetando, de maneira especial, a juventude. Ou seja, a precarização, objetiva e subjetiva, é um pressuposto do capitalismo na sua forma neoliberal.

De maneira consequente e complementar, o Estado também passa a desempenhar maior papel coercitivo dessa população precarizada e cada vez mais alijada do mercado formal de trabalho. Nesse sentido, é também a partir da década de 1970 que o proibicionismo se intensifica e ganha forma pela chamada "Guerra às Drogas" (GD), com as devidas implicações para o tráfico de drogas e como é abordado pelo Estado.

Dada a insuficiência das respostas que visaram saná-la, essa crise se intensifica, sobretudo a partir de 2008 , com a descentralização de produção de bens e serviços ao redor do mundo, expondo os trabalhadores a formas mais sofisticadas de exploração. Essa nova fase do desenvolvimento capitalista se dá pelo aprofundamento da exploração das forças de trabalho, no Brasil exemplificada pelos recentes movimentos de precarização, terceirização e uberização, com destaque para seus impactos na população jovem. Isso significa uma nova forma de organização e remuneração, distantes da regularidade formal e da garantia de direitos, acompanhando o desenvolvimento tecnológico e corroborando ainda o enfraquecimento de formas organizativas da classe trabalhadora e dos fundos públicos de seguridade social. As consequências dessas novas formatações são visíveis na desestruturação da sociedade salarial e na acentuação das desigualdades (Antunes, 2018).

Intentando fugir de visões irrealistas, moralismos e apologias, compreenderemos aqui o tráfico, nessa esteira, como uma forma de trabalho que almeja a produção e comercialização de mercadorias (no caso, as drogas ou substância psicoativas - enfocando aqui as ilícitas) para, supostamente, satisfazer necessidades humanas. Contudo, Carneiro (2002) nos alerta que a lógica de ampliação das necessidades humanas difundidas no e pelo capitalismo, na verdade, serve, essencialmente, para os deleites do capital e seu imperativo 
do lucro e acumulação, em vez de potencializarem o desenvolvimento universal das possibilidades e fruições dos homens.

Além disso, conforme aponta Ferraz (2010, p. 158), o caráter ilegal de certas atividades produtivas, no caso do tráfico de drogas, constitui uma "forma eficiente de acumulação do capital". Para Fraga (2003) e Rocha (2015), a proibição em si agrega valor à mercadoria-droga e ao seu mercado. Por exemplo, nada é mais representativo que as estimativas de Teixeira (2016) de que o mercado ilegal apenas da maconha, cocaína, crack e ecstasy no Brasil fature anualmente cerca de $R \$ 14,5$ bilhões. Isso sem considerar seus imbricamentos com o capital financeiro, por meio de esquemas de lavagem de dinheiro, assim como o mercado bélico, de produção armamentista.

Portanto, uma primeira desmistificação importante a ser feita é a de que o tráfico - e, aprofundando mais, as drogas em $\mathrm{si}^{4}$ - seria um "problema" social. Dada a lucratividade desse mercado, ele se torna uma expressão funcional e necessária ao metabolismo social capitalista, com inúmeros imbricamentos e arranjos de poder com o Estado, ou assumindo algumas de suas atribuições, no atendimento de necessidades básicas e na garantia de determinados direitos nos contextos sociocomunitários nos quais se inserem (Hirata \& Grilo, 2017).

Outro aspecto é que o tráfico tem uma geometria intricada, afeita às mutações sóciohistóricas, bem como às particularidades dos diferentes contextos e localidades brasileiros. Falar, portanto, de "tráfico" no singular não significa desconsiderar possíveis diferenças nas formas organizativas. Apesar de serem frequentemente focalizadas a distribuição e comercialização (no atacado e/ou varejo) dessas substâncias, tal atividade também é perpassada e/ou engloba os processos de produção (por meio de plantios ou artificialmente em laboratórios), estando em interface com a esfera do consumo, a partir de múltiplas determinações e mediações econômicas, sociais e políticas. Ademais, cabe a diferenciação

\footnotetext{
${ }^{4}$ Devido ao escopo do artigo e limitações de espaço, não podemos aprofundar as discussões sobre a relação ser humano-drogas e sua indissociabilidade ao longo da história. Apenas gostaríamos de ressaltar que o uso ou consumo de drogas são "prática[s] que atende[m] a necessidades sócio-históricas" (Brites, 2006, p. 43). Na sociabilidade capitalista, elas se tornam mercadorias, agregando ao valor de uso - um meio externo ao homem para a fruição de suas necessidades - um valor de troca, que frequentemente se sobrepõe ao primeiro, caracterizando o fetichismo da mercadoria (Rocha, 2015). Assim, ao serem comercializadas e consumidas, mistificam o encarnamento da própria alienação dos homens que as produzem, expressando as relações sociais das quais são frutos. Isso nos leva a considerar as drogas e as formas como nos relacionamos com elas circunscritas a uma totalidade social, suas múltiplas mediações e determinações reflexivas
} 
entre produtores, grandes agenciadores e vendedores no varejo (em que existem também diversas formas de atuação). Focalizaremos aqui nesse último agrupamento, mais abordado na literatura acadêmica, devido à maior relação com a juventude, pois estes são os meios de inserção e atuação mais comuns para essa parcela, considerando a hierarquia na estrutura organizativa do tráfico (Alberto \& Pessoa, 2018).

Uma dificuldade adicional, reverberando em limitações para nosso exercício analítico, refere-se à conceituação de juventude e sua relação com o trabalho, mais especificamente o tráfico. Machado (2018) atesta a polissemia do conceito de juventude, transitando entre diversas disciplinas do conhecimento, a partir de variadas matizes, aproximações e distanciamentos. Dialogando com o autor, juventude é entendida como uma construção moderna para uma fase de preparação e, em determinado nível, sobreposição com o início da vida adulta, o que nos leva a compreender as condições históricas, oriundas da totalidade social e das particularidades do Brasil e seu processo de formação, que perfazem essa condição juvenil, perpassadas pelas estruturas e antagonismos de classe, raça, cor, etnia, gênero etc. Ao mesmo tempo, faz-nos questionar critérios meramente etários, como os presentes na legislação, ${ }^{5}$ apesar de não ser possível desconsiderá-los totalmente, face o seu caráter normativo.

Além disso, ao abarcar a infância e adolescência, a análise sobre o trabalho traz também alguns de seus dilemas e complexidades. Por exemplo, apesar de proibido no Brasil, existe uma série de dificuldades na tipificação do que seria trabalho infantil (Alberto \& Pessoa, 2018). Especificamente sobre o tráfico, o próprio Estado brasileiro o reconhece como uma das piores formas de trabalho infantil. 6 Nesse caso, temos uma dupla ilegalidade, com a ilicitude do tráfico - decorrente do proibicionismo - somada à do trabalho infantil (com exceção dos casos a partir dos 16 anos e aqueles que, entre 14 e 16 anos, desenvolvam suas atividades de trabalho na condição de jovem aprendiz).

A despeito dessas limitações, a escolha pela juventude e o trabalho juvenil, e não apenas infância e adolescência, se deve pela necessidade de incorporação de um contingente de pessoas que, dadas suas condições, compõem estrategicamente a estrutura

\footnotetext{
5 A Lei Brasileira n. 12.852, de 5 de agosto de 2013, define juventude como o período de 15 a 29 anos.

${ }^{6}$ Decretos brasileiros n. 3.597, de 12 de setembro de 2000, e n. 6.481 , de 12 de junho de 2008.
} 
do tráfico no Brasil (Fraga, 2003), assim como são afetadas primordialmente pelas recentes mutações do mundo do trabalho, e que seriam desconsideradas se levássemos em conta somente o recorte etário. Segundo Machado (2018, pp. 544-545),

[s]er jovem no Brasil historicamente significa, para a maior parcela da população, ter uma inserção precoce nas dinâmicas presentes no mundo do trabalho, em sua grande parte precarizado e sem perspectiva de profissionalização ou acesso a direitos sociais e trabalhistas, com o único intuito de garantir a sua própria subsistência, acesso a bens de consumo ou ainda contribuir para as despesas familiares.

Em suma, para que o tráfico exista - assim como as drogas -, é necessário trabalho. Nesse caso, a juventude desempenha um papel de extrema importância, sobretudo aquela que vive em condições de pobreza. Portanto, debruçar-se analiticamente sobre ele é considerar que, para um contingente considerável, a associação ao tráfico é uma forma de garantir sua própria reprodução, a partir dos ganhos advindos da venda de suas forças de trabalho. Valendo-nos das palavras de Feffermann (2008, p. 3), "o jovem trabalhador do tráfico de drogas não entra no mundo do crime: ele entra no mundo do trabalho. Esse mundo do trabalho é fora da lei, mas é o mundo do trabalho".

Como aponta Zaluar (2000), há luta, reflexão e negociação na compreensão dos pobres sobre sua realidade. A entrada no mundo do trabalho pelo tráfico, segundo a autora, pode ser entendida como uma das formas dessas resistências à falta de um projeto alternativo de sociedade, sendo identificada por ela como "revolta", que pode conduzir às formas violentas, à criminalidade. Nesses contextos, há também o afastamento de modelos rígidos de moralidade, a partir do momento em que se identifica o bandido como defensor do trabalhador em locais com pouca inserção e atuação do Estado (ao menos no que se refere à garantia de direitos e políticas sociais, pois sua atuação nessas localidades se dá, basicamente, por meio do aparato repressivo, criminalizante e genocida). Assim, a posição de "traficante" é relativizada, pois as condições de vida os aproximam do trabalhador, ao contrário da polícia, principal representante - e sinônimo - do Estado, com quem não têm tal identificação e se veem antagonicamente. 
Não se trata, por outro lado, de romantizar a posição de revolta. Isso porque os traficantes "não são reformistas nem revolucionários. Não lutam por relações mais justas entre ricos e pobres, fortes e fracos. Suas ações podem ser interpretadas como uma revolta individual contra as condições adversas sob a forma de recusa ao trabalho destinado à população pobre" (Zaluar, 2000, p. 166). O que há é uma identificação com o opressor, que, por sua vez, não é exclusiva à classe trabalhadora pobre, algo também apontado por Feltran (2018), que, ao analisar o Primeiro Comando da Capital (PCC), constata que essa identificação acontece para que seja possível acessar e usufruir de bens materiais e status e fazer dinheiro para a fraternidade (como eles se reconhecem), numa luta contra o sistema, mas que não almeja romper com ele, e, sim, modificar sua gerência e o modo de gerir.

No entanto, em uma sociabilidade regida pela contradição capital-trabalho e imperativo do lucro, esses sujeitos não passam ilesos pelas consequentes exploração e alienação inerentes ao trabalho no modo de produção capitalista e consequentes mecanismos ideológicos. Não obstante, devido à sua ilicitude - circunscrita à realidade brasileira -, o tráfico de drogas adquirirá algumas especificidades que, ao se utilizar, sobretudo, de uma parcela da população jovem pauperizada (entre outros elementos que veremos no decorrer do artigo), intensificará essa lógica de exploração - numa superexploração da força de trabalho (Marini, 2005; Ferraz, 2010) - e de dominação e opressão, com exposição constante à sua faceta violenta (Vilela \& Barros, 2016) e consequências, como a criminalização e extermínio.

\section{Resultados e discussão}

Juventude e o trabalho no tráfico de drogas: panorama brasileiro

Mas, então, quem é essa juventude pauperizada, que compõe a base do tráfico no país, estando mais afeito ao seu caráter exploratório e dominador? Os dados do Infopen Levantamento Nacional de Informações Penitenciárias (Brasil, 2017) começam a nos dar algumas pistas. Das 726.712 pessoas encarceradas no país, 28\% (176.691 pessoas) estavam 
presos(as) por "associação"7 com o tráfico de drogas. Dessa população geral encarcerada, temos que: $30 \%$ têm de 18 a 24 anos e $25 \%$ de 25 a 29 anos, $64 \%$ são negros(as), $51 \%$ com ensino fundamental incompleto. Buscando compreender as diferenças de gênero, observamos que, enquanto $26 \%$ dos homens estavam presos por "associação" ao tráfico, a porcentagem de mulheres era de $62 \%$.

Acerca dos adolescentes e jovens em cumprimento de medida socioeducativa, o levantamento do Sistema Nacional de Atendimento Socioeducativo (Sinase), realizado em 2016, mostra que, de um total de 26.450 adolescentes e jovens, 6.254 (22\%) cumprem medida por delito análogo ao tráfico de drogas. Desses jovens que estão com restrição ou privação de liberdade, $96 \%$ são pessoas do sexo masculino e 59,08\% foram considerados de cor parda/preta. No que diz respeito à faixa etária, 57\% dos adolescentes e jovens têm entre 16 e 17 anos, $23 \%$ têm entre 18 e 21 anos, $17 \%$ está na faixa etária entre 14 e 15 anos e $2 \%$ têm entre 12 e 13 anos (Brasil, 2018). O levantamento não trouxe dados relativos à escolaridade dessa população.

Apesar da relevância, os dados carecem de aprofundamento e complementação sobre a juventude "na ativa". Para isso, nos valeremos de pesquisa do Observatório de Favelas e de outros estudos sobre o tema. De acordo com o estudo supracitado, o perfil desses jovens é de homens, negros, de famílias numerosas, com baixo nível socioeconômico e chefiadas por mulheres, alto índice de evasão escolar e experiências anteriores de trabalho informal e precário. A maioria dos entrevistados (62,8\%) tinha entre 16 e 24 anos, sendo que $54,4 \%$ ingressaram no tráfico entre 13 e 15 anos de idade (Willadino, Nascimento \& Silva, 2018).

A despeito de abordar uma realidade local (município do Rio de Janeiro), resguardando suas particularidades, ao ser analisada em conjunto com os levantamentos (Infopen e Sinase), os dados nos fornecem um importante panorama. Adicionalmente, cabe ressaltar que tal perfil é corroborado pela literatura. De acordo com a revisão integrativa de Alberto e Pessoa (2018), no caso do trabalho infantil no tráfico, a maioria é de adolescentes,

\footnotetext{
${ }^{7}$ Colocamos o termo associação entre aspas, pois a legislação brasileira (Lei n. 11.343, de 2006) não define critérios objetivos para a diferenciação entre usuário e traficante. Assim, temos que a tipificação de traficante e o julgamento por agentes da lei e operadores do direito são, frequentemente, embasados em preceitos de classe e raça, numa lógica de criminalização racial e da pobreza.
} 
negros e pardos, com baixa escolaridade e que abandonaram a escola, tendo grandes dificuldades para encontrar emprego.

No que diz respeito à dinâmica e relações de trabalho, Willadino et al. (2018) apontam que as funções mais desempenhadas pelos jovens eram as de "vapor", que é a venda no varejo das drogas $(25,7 \%)$, e soldado $(24,5 \%)$, ficando na contenção e linha de frente dos confrontos armados. Também são comuns as de olheiro/fogueteiro, embaladores, aviões ou mulas (no transporte das drogas) e gerentes (Cruz Neto, Moreira \& Sucena, 2001; Fraga, 2003; Rocha, 2013; 2015; Alberto e Pessoa, 2018). Sobre a carga horária, 26,1\% dizem trabalhar de 10 a 12 horas por dia, enquanto 36,8\% em jornadas de mais de 12 horas por dia. Além disso, 48,3\% dos entrevistados afirmou não ter dia de folga. Acerca dos rendimentos, a maioria $(51,7 \%)$ afirmou receber entre 1.000 e 3.000 reais e $25,6 \%$ até 1.000 reais (Willadino et al., 2018).

Meirelles (2008), ao analisar a trajetória de vida e trabalho de homens jovens que atuaram, de 1990 a 2006, no tráfico de drogas varejista em favelas do Rio de Janeiro/RJ, também constatou jornadas intensas em dois turnos de 12 horas, marcadas por atividades de risco e tensão. Alberto e Pessoa (2018) apontam para a existência de casos em que há uma flexibilização da carga horária, de acordo com a demanda e o número de trabalhadores, e do pagamento, com o valor pago dependendo não só das atividades desempenhadas, mas do faturamento da boca de fumo, expressão acionada em referência aos pontos de venda de psicoativos ilícitos. Também é comum que, antes de ingressarem no tráfico, os jovens, sobretudo em suas adolescências, tenham tido contato precoce com o mundo do trabalho, por meio de circunstâncias também precárias e insuficientes para atender às suas necessidades e de suas famílias (Fraga, 2003). Inclusive, nos casos de crianças e adolescentes, o trabalho precoce e ilegal é visto como instrumento de prevenção das ditas "marginalidade" e "delinquência" (Rodrigues \& Fraga, 2018).

Em suma, por também ser trabalho (Fefferman, 2008), o panorama encontrado apresenta uma série de similitudes e atravessamentos com o da parcela da juventude brasileira inserida no mercado de trabalho legal, marcado pela informalidade, flexibilização e precarização das condições de trabalho, alta rotatividade, inúmeras dificuldades ou impossibilidades em conciliar trabalho e estudo (com abandono precoce do sistema 
educacional), entre outros (Furtado, 2016). Além disso, a inserção desses sujeitos no tráfico se relaciona com as altas taxas de desemprego da população jovem. Segundo dados da Pesquisa Nacional por Amostra de Domicílios, de 12.195 milhões de desempregados no Brasil ao final de 2018, 3.946 milhões tinham entre 18 e 24 anos. A taxa de desemprego nessa parcela foi a maior: $25,2 \%$, mais que o dobro da geral, 11,6\% (Lameiras, Carvalho \& Corseuil, 2019).

Por fim, apesar da predominância de homens, é necessário refletir sobre as mulheres no mercado de drogas (vide dados de encarceramento feminino do Infopen), sendo representativo o número de trabalhos que buscaram compreender os sentidos dessa atividade para mulheres e suas especificidades, rompendo com estereótipos de gênero presentes, inclusive, na academia (para citar alguns: Souza, 2009; Helpes, 2014; Cortina, 2015; Barcinski \& Cúnico, 2016; Fraga \& Silva, 2017). Em suma, os elementos de uma condição de trabalho e vida já pauperizados e precários se consubstanciam ao fato de serem mulheres, numa sociedade de estrutura patriarcal, racista e classista, trazendo e aprofundando elementos de opressão à exploração capitalista.

Juventude no tráfico de drogas: superpopulação relativa e superexploração da força de trabalho

A partir do exposto, argumentaremos que as relações e condições de trabalho imperantes no tráfico para boa parte dessa população jovem configuram uma situação de intensificação da precariedade e superexploração da força de trabalho, seguindo a própria dinâmica do mundo de trabalho e projeto neoliberal, mas também de acordo com as particularidades da condição de capitalismo dependente do Brasil. Conforme mencionado, a superexploração da força de trabalho é sistematizada por Ruy Mauro Marini, entre outros no âmbito da TMD, na tentativa de compreender as determinações históricas de nossa dependência e subordinação.

Segundo o autor, ela surge como forma de as burguesias nacionais compensarem as trocas desiguais com o centro do capitalismo, isto é, de tentarem dirimir as perdas nas transferências de valor para os países de economia central capitalista, que vendem suas 
mercadorias para a periferia a preços superiores de seus valores e compram dela a preços inferiores. Por isso, superexploram a força de trabalho a partir de três mecanismos, isolados ou combinados: a intensificação do trabalho; a prolongação da jornada; e a expropriação de parte do trabalho necessário ao trabalhador, remunerando-o abaixo do seu real valor (Marini, 2005).

A partir dos dados apresentados, podemos observar todos os três mecanismos que constituem a superexploração da força de trabalho nos jovens pauperizados que compõem a base da rede do tráfico de drogas. Por mais que sejam atividades predominantemente do "ramo de prestação de serviços", a subtração das condições necessárias para o trabalhador repor sua força de trabalho estão presentes. Alguns podem questionar que os rendimentos de boa parte desses jovens são superiores à renda per capita do Brasil ( $\$ 1.373$ em 2018) e dos territórios periféricos e pauperizados onde vivem. Contudo, as condições de trabalho precarizadas, intensas e prolongadas jornadas, aguçadas pela ilegalidade, a inexistência de regulamentações trabalhistas, o lucro que geram a partir de suas atividades - bem como a lucratividade do mercado como um todo - e a sua apropriação pelos chefes do tráfico, assim como os riscos envolvidos, configuram a superexploração. Relacionado a isso, o próprio estudo de Willadino et al. (2018) apresenta um dado interessante: 12,6\% dos jovens trabalham concomitantemente em outros lugares. Isso demonstra que o nível de superexploração faz com que tenham que procurar outras fontes de renda para sua reprodução.

Vale ressaltar que o rendimento acima do que provavelmente conseguiriam no mercado formal, além de ser um importante atrativo para os jovens, também contribui, juntamente com a própria dinâmica de trabalho, para que boa parte deles não conceba sua atividade como um trabalho e, consequentemente, não perceba a exploração que lhes acomete. Rocha $(2015$, p. 64$)$, em sua pesquisa com adolescentes que trabalhavam como "mulas" transportando drogas pela fronteira do Brasil e Paraguai, identificou "uma recusa ao trabalho formal, por considerá-lo como exploração, e não reconhecerem que também estão submetidos à exploração no trabalho prestado ao tráfico de drogas".

Faria e Barros (2011, p. 536), em pesquisa sobre as condições econômicas e políticosociais das pessoas aliciadas pelo tráfico, apontam que, em meio a condições de vida 
marcadas "pela precarização das relações de trabalho, pelo desemprego e pelo apelo consumista afinados com as premissas econômicas neoliberais", o tráfico aparece como possibilidade concreta na vida das pessoas, sobretudo na da juventude pauperizada. Dessa forma, atende necessidades objetivas, decorrentes das condições de vida subalternizada, e as subjetivas, fomentadas por um modelo de sociedade individualista e que se ancora numa noção liberal de cidadania por meio do consumo (Cruz Neto et al., 2001; Fraga, 2003; Faria \& Barros, 2011).

Em consonância com Ferraz (2010) e Rocha (2015), consideraremos esses jovens trabalhadores que compõem a base do tráfico de drogas, perpassados pela pobreza e precarização, como parte do exército industrial de reserva (EIR) e superpopulação relativa, sendo produto necessário e alavanca da acumulação capitalista (Marx, 1867/2013). Para Marx (1867/2013), existem três formas de superpopulação relativa: "a) flutuante, constituída por aqueles repelidos e atraídos aos postos de trabalho constantemente; b) latente, englobando os trabalhadores rurais compelidos a saírem do campo e se tornarem trabalhadores urbanos; e c) estagnada, com os trabalhadores em ocupações irregulares, cujas condições de vida estão "abaixo do nível médio normal da classe trabalhadora" (Marx, $1867 / 2013$, p. 873).

Portanto, a juventude da base do tráfico compõe a superpopulação relativa estagnada. Seguindo Marx (1867/2013, p. 874), deveríamos abstrair da superpopulação relativa estagnada os "vagabundos, delinquentes, prostitutas, em suma, [o] lumpemproletariado propriamente dito". Poderíamos, então, desconsiderar os traficantes, especialmente os que se encontram em condições de vida subalternizadas, da superpopulação relativa, caracterizando-os como esse "trapo de proletariado" (/umpemproletariado). Contudo, entendemos que a categoria lumpemproletariado é inadequada para englobar esses sujeitos na base de atividades ilícitas no fluxo das drogas (produção e/ou comercialização), ainda mais em nossa condição de capitalismo dependente. Ainda em concordância com Ferraz (2010), discordamos de tal categorização, afinal, não é o caráter de ilicitude que irá fazer com que essa atividade deixe de contribuir para o acúmulo de capital. Ademais, ao revisitar a obra de Marx, a autora aponta que o lumpemproletariado não pode ser entendido somente por conta de sua situação de pauperização. Trata-se de 
uma categoria política (mesmo com desdobramentos econômicos), que não "diz respeito a uma função econômica no modo de produção capitalista" (Ferraz, 2010, p. 260), em detrimento da superpopulação relativa, que seria econômico-política.

Dessa forma, a estrutura organizacional hierárquica do tráfico apresenta um caráter empresarial de flexibilidade, utilizando-se desses jovens como superpopulação relativa estagnada na base da subcontratação, remuneração com base no desempenho e produtividade e mecanismos que se assemelham à terceirização, contratando empresas, serviços e/ou pessoas "externas" para a realização de ações específicas. Na pesquisa de Cruz Neto et al. (2001), por exemplo, observou-se logística semelhante a um plano de carreira, com salários flexíveis. Os jovens adentram nessa geometria devido ao "potencial laborativo e à disposição necessária para o desenvolvimento de ações ilegais" (Rocha, 2015, p. 62), suas condições de vida pauperizadas e perpassadas por inúmeras desigualdades, assim como pelas próprias configurações segregatórias do mercado formal de trabalho: exigências formais de qualificação, precarizações das relações e condições de trabalho, desemprego estrutural, entre outras (Alberto \& Pessoa, 2018).

Nesse sentido, considerando o tráfico como trabalho que absorve parte da juventude em condição de EIR e superpopulação relativa estagnada, podemos refletir sobre as possibilidades e obstáculos desses jovens na compreensão da realidade e organização política. O perigo de uma passagem imediata das condições materiais para as culturais principalmente em relação à diferenciação com a classe trabalhadora organizada, vinculada ao mercado formal e seus mecanismos trabalhistas protetivos -, gerou definições generalistas e que não captam o caráter contraditório da realidade, como as de passividade, atraso, apatia política e imediatismo. Tais visões implicam que tal população não seria capaz de se organizar e pensar autonomamente. A pergunta que permanece, então, é: "como poderiam, de fato, pessoas expostas a tal tipo de discriminação e exploração permanecer completamente dóceis ao sistema que as exclui e explora?" (Zaluar, 2000, p. 44). Podemos, por conseguinte, pensar que as condicionalidades de inserção e trabalho no tráfico, propositalmente, contribuem para obstaculizar processos de organização e mobilização desses jovens e, consequentemente, de consciência de classe. No entanto, dado o já exposto, podemos questionar se o tráfico como forma trabalho - e, também, revolta - não 
seria uma possibilidade, entre as parcas, de alguma organização desses jovens como classe trabalhadora - que não é homogênea - ou, ainda, para consciência de classe? O trabalho no tráfico confere algum significado a eles como sujeitos políticos?

Especificamente sobre as mulheres, conforme aponta Helpes (2014), para além dos casos em que a relação com o tráfico é impulsionada por questões afetivo-amorosas, ele também se apresenta como possibilidade concreta de aumento dos rendimentos, vide que, em cenários de pauperização, elas aparecem frequentemente como as provedoras e gestoras de suas famílias. Ademais, também não é por acaso que a maioria dessas jovens seja negra, fazendo com que reafirmemos que essa juventude superexplorada pelo tráfico de drogas no Brasil tenha classe, raça, cor, etnia e gênero, moldando as formas que essa exploração irá conformá-la, bem como o conjunto de opressões e violências de tal modalidade produtiva e a própria realidade brasileira.

Nesse sentido, o próprio trabalho juvenil no tráfico e a sua dinâmica demonstram o equívoco das premonições sobre o "fim do trabalho" como valor ou a perda de sua centralidade, ao passo em que se faz fundamental compreender as mutações qualitativas do mundo do trabalho, que apresentam traços comuns ao redor do mundo (Antunes, 2015; 2018). É importante ressaltar que o capital não se autovaloriza sem o trabalho humano, conforme Marx já apontava; logo, mesmo precarizado ou ilegal, continua sendo trabalho. Devemos reconhecer que a inserção e atividade juvenil no tráfico, nas condições apresentadas, acompanha as reconfigurações do mundo do trabalho, sendo uma das respostas à crise do próprio capital, engendrada nas estruturas e processos de desenvolvimento do Brasil como capitalismo dependente.

Assim, constatamos uma dupla condição de dominação da juventude pauperizada que vende sua força de trabalho no mercado ilegal de drogas: sejam eles "livres" atravessados por condições precárias e de superexploração, aguçadas pela ilegalidade proveniente do proibicionismo; sejam "presos", servindo, inclusive, como argumento ideológico do Estado para a intensificação da lógica de controle, criminalização e genocídio de determinadas parcelas populacionais, na forma de "inimigos internos" e responsáveis pelas mazelas e estruturas sociais antagônicas (Rocha, 2013). Nesse sentido, o proibicionismo por meio da GD é uma política de Estado que foca na população jovem, 
negra, pauperizada e periférica, contribuindo para aguçar o cenário de superexploração, aliado ao reforçamento do controle, criminalização e extermínio dessa parcela populacional.

Nisso, é fortalecida a condição de dependência do país, com o proibicionismo agregando valor às mercadorias e lucratividade ao mercado e, portanto, contribuindo para transferência desse valor para os países de economia central - sobretudo quando consideradas as ínfimas relações com o mercado financeiro. Ao mesmo tempo, amplia os braços imperialistas estadunidenses pela expansão do mercado de armas e servindo, também, como justificativa para intervir nos países da América Latina (considerados culpados pela produção das drogas).

Concordando com Bortolozzi (2014, p. 26), tratar dessa juventude de maneira unilateral como socialmente excluída ou marginalizada é desconsiderar ou analisar insuficientemente o seu papel e funcionalidade no modo de produção capitalista dependente brasileiro: "o trabalho infantil [e o juvenil, de modo geral] não pode ser pensado como um fenômeno marginal, mas como um elemento essencial para a reprodução do capitalismo". O alijamento do mercado formal de trabalho, do sistema educacional, as condições pauperizadas e o baixo nível socioeconômico de vida, bem como as carências (ou mesmo ausências) estatais na garantia de bem-estar social, não podem ser entendidos como sinônimo de exclusão ou marginalidade social e/ou econômica. Observamos, assim, um caráter contraditório, com essas exclusões ou marginalizações das escolas, do sistema de saúde, no âmbito do trabalho etc. contribuindo para que ocupem uma posição estratégica no modo de produção capitalista brasileiro, tendo sua força de trabalho superexplorada. Atrelado a isso, são alvos preferenciais do tráfico e do braço repressivo, criminalizante e genocida do Estado, na sua configuração neoliberal e faceta penal.

Como Marini (2005) coloca, uma das várias consequências da superexploração no capitalismo dependente é a cisão da circulação e consumo de mercadorias. Por um lado, temos o trabalhador cuja força e trabalho é superexplorada (as maiorias populares pauperizadas), constituindo um contingente de baixo consumo, e, por outro, temos uma esfera de alto consumo, referente às elites minoritárias quantitativamente. Por mais que o tráfico apareça para a juventude pauperizada como uma possibilidade de "inclusão" pela via do consumo, o parco ou ausente acesso aos bens socialmente produzidos, sobretudo os que 
se atrelam ideologicamente a condições socioeconômicas consideradas vantajosas, de status etc., não significa uma situação anterior de exclusão ou marginalidade da esfera econômica/produtiva da sociedade. Pelo contrário, representam a função estratégica que desempenham, como superpopulação relativa superexplorada em nosso capitalismo dependente.

Por fim, compreender o tráfico de drogas ilícitas como uma atividade produtiva e o trabalho que Ihe é necessário, implica em apreender suas vicissitudes, tal como a realidade e suas contradições, rompendo com maniqueísmos de bom ou mau, vítimas ou algozes ou, mesmo, de condenações vazias versus apologias (Rocha, 2013; Cruz Neto et al., 2001). O que buscamos demonstrar é que abordar o tráfico significa, antes de tudo, adentrar nas entranhas da sociabilidade da qual ele é expressão e, portanto, conforma. Ou seja, por que o tráfico existe e se faz necessário? Mais, o que faz com que os jovens, dentre outras pessoas, busquem-no e necessitem dele?

Assim, antes de dirigirmos nossas críticas a essa modalidade produtiva - o que é imperativo -, devemos olhar para o modo de produção vigente, entendendo que parte dos antagonismos, elementos de exploração e dominação percebidos no tráfico são oriundos desse sistema, estando presente, inclusive, em outras "atividades laborais". Nesse sentido, seu caráter ilegal, proveniente do proibicionismo, não contribui para um melhor panorama; pelo contrário, ao mesmo tempo em que agrega valor às mercadorias drogas ilícitas e lucratividade ao seu mercado, também propicia mais precarização e exploração, sobretudo, da juventude pauperizada que constitui sua base, estando também mais afeita à sua violência intrínseca e imperativa (Vilela \& Barros, 2016), juntamente com as inúmeras violências estatais. Ademais, no caso da juventude, devemos nos atentar para as especificidades e diferenças referentes ao trabalho para crianças, adolescentes e adultos, bem como para suas condições de vida, diversos contextos de inserção, formas de atuação e como vêm sendo historicamente - e na atual conjuntura - incorporados pelo modo de produção e reprodução capitalista brasileiro.

\section{Considerações finais}


O trabalho no tráfico realizado pelos jovens pauperizados, predominantemente negros, periféricos, entre outros elementos que caracterizam uma condição de vida subalterna no Brasil, mostra-se em consonância com as mutações ocorridas no "mundo do trabalho", em decorrência da crise do capitalismo monopolista. Não à toa, abastece-se, prioritariamente, dessa parcela populacional, apresentando-se como opção viável e possibilidade de "ascensão social", diante das inexistentes ou parcas - e, também, precarizadas - opções do mercado formal e informal de trabalho. Novos estudos devem buscar a compreensão dessas mutações e novas configurações e suas múltiplas mediações objetivas e subjetivas, considerando os processos de precarização e flexibilização, aliado ao avolumamento do EIR e superpopulação relativa na forma neoliberal capitalista presente e particularidade dependente brasileira.

$\mathrm{Na}$ presente conjuntura, de ofensiva do capital e projeto neoliberal, suas contrarreformas (trabalhista, previdenciária etc.), gerando ainda mais informalidade, flexibilização e precarização, perda de direitos e com o aumento do desemprego estrutural e da superpopulação relativa, o tráfico tende a se fortalecer ainda mais para esses jovens como uma alternativa concreta e vantajosa. Estando esse tráfico vinculado ao proibicionismo, não pode ser abordado em sua complexidade e com as devidas alterações, sem as prementes mudanças políticas, com legalização e regulamentação da produção, comercialização e consumo de drogas - assim como o fortalecimento da prevenção, promoção de saúde social e assistência/cuidado aos consumidores dessas substâncias que necessitarem. Na mesma esteira, questionamos: todos estes fatores que constituem o mundo do trabalho atualmente, em conjunto com a promoção da ideologia empreendedorista, não são, justamente, os que embasam e orientam a dinâmica e relações de trabalho no tráfico? As condições de trabalho de boa parte dos trabalhadores brasileiros não se aproximam ou, mesmo, assemelham, cada vez mais, a dos jovens e pauperizados traficantes?

\section{Referências}


Alberto, M. F. P., \& Pessoa, M. C. B. (2018). Trabalho infantil no tráfico de drogas: o que diz a produção acadêmica?. Documento Base do Grupo Técnico "Prevenção do Envolvimento de Crianças e Adolescentes no Tráfico de Drogas". Fórum Nacional de Prevenção e Erradicação do Trabalho Infantil. Recuperado de http:/ / www.fnpeti.org.br/arquivos//biblioteca/8fe826ffa8d5cd491027d212ef49b22 1.pdf.

Antunes, R. (2015). Adeus ao trabalho?: ensaio sobre as metamorfoses e a centralidade no mundo do trabalho. São Paulo: Cortez. (Trabalho original publicado em 2000).

Antunes, R. (2018). O privilégio da servidão: o novo proletariado de serviços na era digital. São Paulo: Boitempo.

Barcinski, M., \& Cúnico, S. D. (2016). Mulheres no tráfico de drogas: retratos da vitimização e do protagonismo feminino. Civitas - Revista de Ciências Sociais, 16(1), 59-70.

Bortolozzi, R. M. (2014). Sentido do trabalho para jovens trabalhadores da economia da droga: exame retrospectivo. Dissertação de mestrado, Universidade de Brasília, Brasília, Brasil.

Brasil. (2017). Levantamento Nacional de informações penitenciárias/Infopen. Brasília: Ministério da Justiça e Segurança Pública.

Brasil. (2018). Levantamento Anual Sinase 2016. Brasília: Ministério dos Direitos Humanos.

Brites, C. M. (2006). Ética e uso de drogas: uma contribuição da ontologia social para o campo da saúde pública e da redução de danos. Tese de doutorado, Programa de Estudos Pós-Graduados em Serviço Social, Pontifícia Universidade Católica de São Paulo, São Paulo, Brasil.

Carneiro, H. (2002). As necessidades humanas e o proibicionismo das drogas no século XX. Outubro, $6,115-128$.

Cortina, M. O. C. (2015). Mulheres e tráfico de drogas: aprisionamento e criminologia feminista. Revista Estudos Feministas, 23(3), 761-778.

Cruz Neto, O., Moreira, M. R., \& Sucena, L. F. M. (2001). Nem soldados nem inocentes: juventude e tráfico de drogas no Rio de Janeiro. Rio de Janeiro, Brasil: Editora Fiocruz.

Faria, A. A. C., \& Barros, V. A. (2011). Tráfico de drogas: uma opção entre escolhas escassas. Psicologia \& Sociedade, 23(3), 536-544. 
Feffermann, M. (2008). Cotidiano dos jovens trabalhadores do tráfico. Segurança Urbana e Juventude, $7(2), 1-14$.

Feltran, G. (2018). Irmãos: uma história do PCC. São Paulo: Companhia das Letras.

Ferraz, D. L. S. (2010). Desemprego, exército de reserva, mercado formal-informal: rediscutindo categorias. Tese de Doutorado, Universidade Federal do Rio Grande do Sul, Porto Alegre, Brasil.

Fraga, P. C. P, \& Silva, J. K. N. (2017). A participação feminina em mercados ilícitos de drogas no Vale do São Francisco, no Nordeste brasileiro. Tempo Social, 29(2), 135-158.

Fraga, P. C. P. (2003). Da favela ao sertão: juventude, tráfico e institucionalidade. In P. C. P. Fraga \& J. A. S. Iulianelli (Orgs.). Jovens em tempo real (pp. 82-107). Rio de Janeiro, Brasil: DP\&A Editora.

Furtado, A. (2016). Desemprego entre jovens: situação do Brasil e lições da experiência internacional. Estudo Técnico. Brasília: Câmara dos Deputados. Recuperado de https://www2.camara.leg.br/atividade-legislativa/estudos-e-notastecnicas/publicacoes-da-consultoria-legislativa/areas-daconle/tema7/2016_12418_desemprego-entre-jovens_adolfo-furtado.

Harvey, D. (1998). Condição pós-moderna: uma pesquisa sobre as origens da mudança cultural. São Paulo: Edições Loyola. (Trabalho original publicado em 1989).

Helpes, S. S. (2014). Vidas em jogo: um estudo sobre mulheres envolvidas com o tráfico. Dissertação de mestrado, Programa de Pós-Graduação em Ciências Sociais, Universidade Federal de Juiz de Fora, Juiz de Fora, Brasil.

Hirata, D. V., \& Grillo, C. C. (2017). Sintonia e amizade entre patrões e donos de morro: perspectivas comparativas entre o comércio varejista de drogas em São Paulo e no Rio de Janeiro. Tempo Social, 29(2), 75-98.

Lameiras, M. A. P., Carvalho, S. S., \& Corseuil, C. H. L. (2019). Mercado de Trabalho. Carta de Conjuntura, 42, 89-112.

Machado, P. H. S. S. (2018). A condição juvenil periférica: notas introdutórias para entender a juventude no capitalismo dependente. REBELA, 8(3), 516-552. 
Marini, R. M. (2005). Dialética da dependência, 1973. In R. Traspadini \& J. P. Stedile (Orgs.). Ruy Mauro Marini: vida e obra (pp. 131-172). São Paulo. Expressão Popular. (Trabalho original publicado em 1973).

Marx, K. (2010) Manuscritos econômico-filosóficos. São Paulo: Boitempo Editorial. (Trabalho original publicado em 1844).

Marx, K. (2013). O Capital: crítica da economia política. Livro l: o processo de produção do capital. São Paulo: Boitempo Editorial. (Trabalho original publicado em 1867).

Meirelles, Z. V. (2008). Nas viradas da vida: jovens que romperam com o mercado do tráfico de drogas em favelas na cidade do Rio de Janeiro. Tese de doutorado, Fundação Oswaldo Cruz, Escola Nacional de Saúde Pública Sergio Arouca, Rio de Janeiro, Brasil.

Rocha, A. P. (2013). Proibicionismo e a criminalização de adolescentes pobres por tráfico de drogas. Serviço Social \& Sociedade, (115), 561-580.

Rocha, A. P. (2015). Relações de trabalho no narcotráfico: exploração, riscos e criminalização. Argumentum, $7(1), 55-68$.

Rodrigues, L. B., \& Fraga, P. C. P. (2018). Justiça e variáveis legais: processos contra adolescentes varejistas do tráfico de drogas. Sociologia On Line, 3, 57-78.

Rother, E. T. (2007). Revisão sistemática $\times$ revisão narrativa. Acta Paulista de Enfermagem, $20(2), v-v i$.

Souza, K. O. J. (2009). A pouca visibilidade da mulher brasileira no tráfico de drogas. Psicologia em Estudo, 14(4), 649-657.

Teixeira, L. S. (2016). Impacto econômico da legalização das drogas no Brasil. Consultoria Legislativa da Câmara dos Deputados. Brasília, Brasil: Câmara dos Deputados. Recuperado de https://www2.camara.leg.br/atividade-legislativa/estudos-e-notastecnicas/publicacoes-da-consultoria-legislativa/areas-da-conle/tema 10/impactoeconomico-da-legalizacao-das-drogas-no-brasil.

Vilela, T., \& Barros, V. A. (2016). O acerto de contas no trabalho do tráfico de drogas varejista. Gerais: Revista Interinstitucional de Psicologia, 9(2), 162-181.

Willadino, R., Nascimento, R. C., \& Silva, J. S. (2018). Novas configurações das redes criminosas após a implantação das UPPs. Rio de Janeiro: Observatório de Favelas. 
Zaluar, A. (2000). A máquina e a revolta: as organizações populares e o significado da pobreza. São Paulo: Brasiliense.

Recebido em: 26/6/2019

Aprovado em: 17/2/2020 